\title{
Extension Workers' Perceived Effectiveness of Linkages Mechanism with Researchers And Farmers In Edo State, Nigeria.
}

\author{
${ }^{1}$ Okoedo-okojie D. U. and G. E. Okon ${ }^{2}$ \\ ${ }^{1,2}$ Department of Agricultural Economics And Extension ServicesFaculty of Agriculture University Of Benin \\ P.M.B 1154 Benin City, Nigeria
}

\begin{abstract}
The study examined extension workers' perception of linkage mechanisms with researchers and farmers in Edo state, Nigeria. A total of seventy (70) respondents were used for the study, which comprised of 28 extension agents and 42 fadama facilitators in contact with researchers and farmers. Data were generated with the use of structured questionnaire and analysed using means. Results showed that result demonstration, agricultural show, joint campaign and field trip where the effective linkage mechanism $(M=3.77)$ and $(M=3.36)$ between extension agents and researchers and extension agents and farmers respectively.Also that method demonstration $(M=4.40)$ was most effective method of transferring technology to farmers and that the linkages with researchers $(M=26.29)$ is more effective compared to farmers $(M=23.36)$. The study recommends intensified use of personal letters as linkage mechanism both with researchers and farmers and the encouragement of farmers in joint use of mobile vans and tape recorders.
\end{abstract}

\section{Introduction}

The performance of the Nigeria agricultural sector in the economy of Nigeria is evidently unsatisfactory (Adetunjiet al, 2002). This could be as a result of the weak linkage between researchers, extension personnel and farmers, as it has be noted by American Society of Agricultural Biological Engineer $\operatorname{ASABE}(2005)$ that there is no dearth of knowledge and new technologies in agriculture but these rarely reach farmers especially those in developing countries. Traditionally, knowledge and technologies are expected to flow from knowledge centresi.e. International Agricultural Research Centres (IARCS) and Advance Research Institute (ARIS) to National Agricultural Research system (NARS) and from there to the National Agricultural Extension System (NAES) and the Non- Government Organization (NGOs) to farmers in practice however very little of this has happened in part because NARS and NAES are traditional decoupled in many developing countries and information channels between them are weak, thus much information still remains in accessible to farmers.

The very weak linkages in the Research-Extension-Farmer-Input Linkage System (REFILS), in Nigeria as in most developing countries have been a major limiting factor to increase food production and sustainable development.

For agro-technologies to be relevant to local needs, researchers, extension workers and farmers must play important roles in identifying research problems adapting the recommendations to local conditions and providing feedback to researchers about the innovations that have been developed (Agbamu 1998). Effective communication links between researchers and extensionistare vital in the modification of technological recommendations and in initiating further research.Such links enable new technologies and management practices to be suited to local ecological conditions. The participation of extension workers in adaptive research trials allows them to become familiar with the technologies they are expected to promote and also helps to ensure that the sociological dimensions of farming are not neglected.

Linkage activities are usually managed at verifying administrative levels; national regional, state and local levels. The agricultural research and extension system identifies farm families as their target and the hub around which researchers and extensionist focus their actions.

Agbamu, (1998) further asserted that the constraints which hinder research extension linkage potentially affect the agricultural output of farmers, whereas effective links will allow farmers to enhance their output through the availability of farming innovations.

By 1982 research - extension - linkage practitioners modifies the linear model and evolved a Farming System Research and Extension (FSRE) Approach with emphasis on a bottom up technology generation and transfer system described as the technology triangle relationship among the three stakeholders, i.e Research, Extension and Farmers, (Agbamu, 2000). Olowu and Windapo (1995) identified a complex relationship in which there are relational overlaps such overlaps are linkage points between them which point to the fact that none of the three can function independently. 
Fig. 1 The connection between the main actors of the agricultural research extension linkage system (technological triangle).

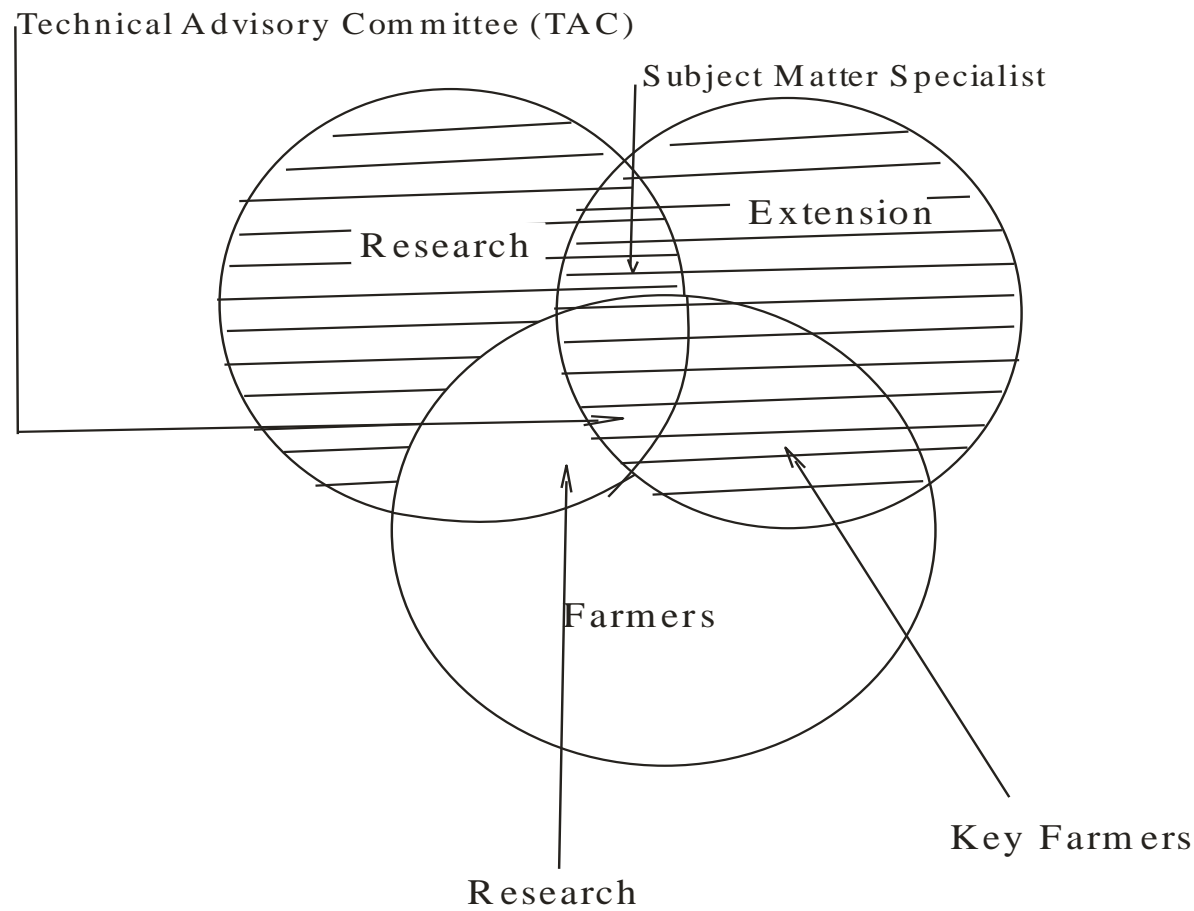

The agricultural research findings are of little use if they are not adopted by farmers. Studies have shown that the achievement of a stable and more productive farming system in a nation like Nigeria results from building a strong link within and between research and technology transfer agencies and the farmers. Research, extension and farmers belong to the agricultural production sub-systems. The three subs systems interlock and hence the interface between them should be managed in the linkage mechanism. The relationship is such that researchers release research results to extension agents who in turn apply the knowledge to assist farmers, and then farmers discuss their farm problems with the extension agents who in turn passes these to the researchers.

Against the background of agricultural information flow to actualize extension delivery, knowledge extension workers' perception of linkage mechanism with researchers and farmers is an issue of research.

\section{Objectives of the Study}

The general objective of this study is to assess extension workers' perceived effectiveness of linkage mechanism with researchers and farmers in Edo State, Nigeria. The specific objectives were to ascertain respondents' perceived effectiveness of linkage mechanism with researchers and farmers; effectiveness and frequency of use of technology transfer methods.

\section{Hypothesis formulated}

A null hypothesis formulated for the study is that there is no significant difference ineffectiveness of extension agents in linkage with researchers and farmers.

\section{Methodology}

The study was carried out in Edo state, Nigeria. A two stage sampling technique was used in selecting respondents for the study. The first stage was to purposively select Agricultural Development Programme (ADP) in Edo state. The next stage was to randomly select 28 extension agents in contact with researchers and farmers, and also 42 fadama facilitators. This gave a total of seventy (70) respondents' perceived effectiveness of linkage mechanism, technology transfer methods and frequency of use with researchers and farmers respectively with the aid of questionnaire validated by expert judgment. Respondents perceived effectiveness of linkage mechanism was measured in a 4 point rating scale of very effective $=4$, effective $=3$, least effective $=2$, and not effective $=1$. Effectiveness of technology transfer method was measured in a 5-point rating scale of very effective coded 5, effective coded 4, undecided coded 3, least effective coded 3 and not effective coded 1 .

Frequency of use of technology transfer method was measured in a 4-point rating scale of very frequent 
coded 4, frequent coded 3, sometimes coded 2, and not at all coded 1. Data were analyzed using mean and hypothesis tested using t-test.

\section{Results and Discussions}

Extension Agents perceived Effectiveness of Linkage Mechanism with Researchers and Farmers

Table 1 showed that result demonstration, agricultural show, joint campaign and field trip where the effective linkage mechanism $(M=3.77)$ and $(M=3.36)$ between extension agents and researchers and extension agents and farmers respectively. Only personal letters $(M=1.40)$ and $(M=1.20)$ was not and effective linkage mechanism between extension agent_and researcher/farmers respectively. This result is an indication that linkage mechanisms that promote good social interaction are more effective linkages between researchextension-farmers to actualize agricultural technologies transfer objectives. This result support the finding of Agbamu (2000) that the participation of extension workers in adaptive research trials allows them to become familiar with the technologies they are expected to promote and also helps to ensure that the sociological dimensions of farming are not neglected.

Table 1: Extension Agents Perceived Effectiveness of Linkage Mechanism with Researchers and Farmer

\begin{tabular}{|c|c|c|c|c|}
\hline \multirow[t]{2}{*}{ Linkage mechanism } & \multicolumn{2}{|c|}{ Researchers } & \multicolumn{2}{|c|}{ Farmers } \\
\hline & Mean & SD & Mean & SD \\
\hline Result demonstration, Agricultural show, joint campaign, field trip & $3.77 *$ & 0.552 & $3.36^{*}$ & 1.189 \\
\hline Joint use of teaching aids, photographs & $3.41 *$ & 0.789 & $3.07 *$ & 1.181 \\
\hline Joint sponsorship of information to farmers and researchers & $3.18^{*}$ & 0.680 & $2.83 *$ & 1.033 \\
\hline Visit to research centers & $3.14 *$ & 0.626 & $2.70 *$ & 0.919 \\
\hline Joint use of technical information & $3.09 *$ & 0.741 & $2.68 *$ & 1.031 \\
\hline Free access to annual reports, bulletins and farm magazines & $2.95 *$ & 0.655 & $2.57 *$ & 0.915 \\
\hline sharing of audio visual Joint programmes on TV and Radio & $2.82 *$ & 0.754 & $2.58 *$ & 0.890 \\
\hline Joint use of mobile vans, tape recorder & $2.54 *$ & 0.780 & 2.36 & 0.848 \\
\hline Personal letters & 1.40 & 0.761 & 1.20 & 0.515 \\
\hline
\end{tabular}

Source: field survey $2010 *$ Effective (mean $\geq 2.50) \quad$ scale: Not effective $=1$, least effective $=2$, effective $=3$, very effective $=4$.

\section{Extension Agents Perceived Effectiveness of Technology Transfer Methods}

Table 2 showed the extension agents perception of effectiveness of technology transfer method. Method demonstration ( $M=4.40)$ was most effective method to transfer technology to farmers. Followed by farm and home visit $(M=4.25)$ and result demonstration $(M=4.19)$. This result agrees with findings of Androulidakiset al (1995) where the perceptions of extension agents were sought about the appropriateness of the educational methods used to reach farmers in Greece. While the non-effective technology transfer method were leaflet $(\mathrm{M}=2.32)$ may be as a result of no proper and effective usage/ application, booklets $(\mathrm{M}=2.30)$, Newsletter $(M=2.20)$, chalk board $(M=2.00)$. The result further showed of all the effective technology transfer methods $(M \geq 3.0)$, radio $(M=3.15)$, telephone $(M=3.09)$ and television $(M=3.04)$ were less effective. This shows that mass method which are ICTs compliance are not as effective as individual and group methods in technology transfer. The implication is more farmers may not be effectively reached with proven technologies from research.

Table 2 Extension Agents Perceived Effectiveness of Technology Transfer Methods

\begin{tabular}{|l|l|l|}
\hline Transfer methods & Mean & SD \\
\hline Method Demonstration - & $4.40^{*}$ & 1.081 \\
\hline Farm and home visit & $4.25^{*}$ & 1.188 \\
\cline { 2 - 4 } & $4.19^{*}$ & 1.371 \\
\hline Result demonstration & $3.86^{*}$ & 1.092 \\
\hline Agric documentary on TV & $3.80^{*}$ & 1.087 \\
\hline Visit to research institute & $3.75^{*}$ & 1.114 \\
\hline Field days & $3.71^{*}$ & 0.951 \\
\hline Workshops & $3.51^{*}$ & 1.056 \\
\hline Exhibitions and displays & $3.49^{*}$ & 0.973 \\
\hline Agricultural show & $3.48^{*}$ & 0.995 \\
\hline Discussion meeting & $3.47^{*}$ & 1.066 \\
\hline Field trip & $3.36^{*}$ & 0.996 \\
\hline Committee meetings & $3.19^{*}$ & 1.059 \\
\hline Films & $3.15^{*}$ & 1.124 \\
\hline Radio & $3.09^{*}$ & 1.087 \\
\hline Telephone & $3.04^{*}$ & 0.893 \\
\hline Television & 2.97 & 0.989 \\
\hline Institutional posters & 2.97 & 1.010 \\
\hline Agricultural magazines & 2.96 & 0.917 \\
\hline Video tape & & \\
\hline
\end{tabular}




\begin{tabular}{|l|l|l|}
\hline Campaign & 2.70 & 1.097 \\
\hline Audio cassette & 2.67 & 1.033 \\
\hline Journals & 2.51 & 1.076 \\
\hline Leaflets & 2.32 & 0.900 \\
\hline Booklets & 2.30 & 0.860 \\
\hline Newsletter & 2.20 & 0.878 \\
\hline Chalk board & 2.00 & 0.795 \\
\hline
\end{tabular}

Source: field survey $2010 *$ Effective (mean $\geq 3.00)$

VII. Frequency of Use of Technology Transfer Method By Extension Agents.

Table 3 shows frequency of technology transfer method by extension agent.

Method demonstration ( $M=2.72$ ) was the highest, hence it was perceived as most effective (table 2). However, none of the technology transfer methods was frequency used i.e., all means were less than three $(\mathrm{M}<3.00)$. This situation can lead to low adaptive significance and appreciation of proven technologies. The implication may be a low utilization level of technologies. This result actualizes the ASABE(2005) that very little of knowledge and technology transfer mechanism has happened from IARCS and ARIS to NARS and NGOs to farmers a further implication is low and unsatisfied performance of the Nigerian agricultural sector and noted by Adetunjiet al(2002), thus a stagnant contribution of agriculture to national GDP in Nigeria.

Table 3 frequency of use of technology transfer method

\begin{tabular}{|l|l|l|}
\hline Transfer methods & Mean & SD \\
\hline Method Demonstration & 2.72 & 0.721 \\
\hline Result demonstration & 2.65 & 0.767 \\
\hline Farm and home visit & 2.57 & 0.778 \\
\hline Discussion meeting & 2.43 & 0.677 \\
\hline Exhibitions and displays & 2.40 & 0.827 \\
\hline Field trip & 2.36 & 0.698 \\
\hline Visit to research institute & 2.35 & 0.794 \\
\hline Agricultural show & 2.22 & 0.619 \\
\hline Agric documentary on TV & 2.19 & 0.772 \\
\hline Field days & 2.19 & 0.730 \\
\hline Committee meetings & 2.19 & 0.670 \\
\hline Workshop & 2.17 & 0.556 \\
\hline Telephone & 2.14 & 0.913 \\
\hline Television & 2.06 & 0.646 \\
\hline Agricultural magazines & 2.04 & 0.614 \\
\hline Video tape & 1.96 & 0.695 \\
\hline Films & 1.94 & 0.693 \\
\hline Radio & 1.93 & 0.684 \\
\hline Institutional posters & 1.86 & 0.734 \\
\hline Campaign & 1.68 & 0.733 \\
\hline Journals & 1.58 & 0.829 \\
\hline Audio cassette & 1.54 & 0.679 \\
\hline Booklets & 1.48 & 0.794 \\
\hline Newsletter & 1.41 & 0.762 \\
\hline Leaflets & 1.40 & 0.732 \\
\hline Chalk board & 1.28 & 0.721 \\
\hline
\end{tabular}

Source: field survey $2010 *$ Frequent $(\mathrm{M} \geq 3.0 \overline{0})$

\section{Difference in effectiveness of Extension Agents in Linkage with Researchersand Farmers.}

Table 4 shows the difference in perceived effectiveness of linkages with researchers and farmers. The mean shows that linkages with researchers $(X=26.29)$ is more effective compared to farmers $(X=23.36)$. The t- value (4.71) is significant at the 5\% level implying that extension agents' communication with researchers is more effective or stronger than with farmers. An explanation for this could be that extension agents visit research centers frequently and also observetheir joint use teaching aids and joint sponsorship of information to farmers. This situation might negate the three sub-system interlock between extension agents, farmers and researchers as the linkage mechanism may favor more of the relationship between extension agent and researchers than between extension agents and farmers. This is may cause deficit or imbalance between agricultural information sources to research and agricultural information dissemination to farmers by extension agents.As the result show that information sourcing from research and information dissemination to farmers by extension agents. This means that information from research is better managed by extension agents than information to farmers. This can cause a gap between basic and adaptive research. Hence agricultural output of 
farmers may be evidently reduced compared to agricultural output from technological experimental field as a result of information technology distortion between research institutes and farmers by extension agents.

Table 4 difference in effectiveness of extension agents' linkages with researchers and farmers

\begin{tabular}{|c|c|c|c|c|}
\hline Linkages & \multicolumn{2}{|c|}{ Effectiveness } & & \\
\hline & Mean & Difference & $\mathrm{t}$ value & Prob* level \\
\hline Researchers & 29.29 & 2.92708 & 4.710 & $0.000 *$ \\
\hline Farmers & 23.36 & & & \\
\hline
\end{tabular}

Source computed from field survey *significant at $5 \%(\leq 0.050)$

\section{Conclusion and Recommendation}

Based on the findings of this study, it is concluded that extension workers in Agricultural Development Programme (ADP) in Edo State, Nigeria, perceived linkage mechanism with researchers and farmers to be effective. Result demonstration, agricultural show, joint campaign and field trip were most effective linkage mechanism.

The following measures are suggested towards improving effectiveness of linkage mechanism. The Agricultural Development Programme (ADP) in Edo state should: (a) intensify the use of personal letters as linkage mechanism both with researchers and farmers inactualizing agricultural technology transfer (b) Encouragefarmers in joint use of mobile vans and tape recorders, which are presently ineffective linkage mechanisms.

To facilitate research-extension -farmers' linkage, the extension workers should be more frequent in their visit to research institutes, use of agricultural journals, television, audio cassettes to facilitate technology transfer and sourcing.

\section{References}

[1] Adetunji,T.AOladeji, J.O.andOlowu, T.A (2002):Citation pattern of Agricultural Extension Research in Nigeria Journals. Journal of Agricultural Extension 6,25-33.

[2]. Agbamu, J.U. (1998): A study on agricultural research-extension linkages: with focus on Nigeria and Japan, Ph.D thesis, Tokyo University of Agriculture.

[3]. Agbamu, J.U. (2000). Agricultural Research-Extension Linkage System: An International Perspective. Agricultural Research and Extension Network, Network paper No. 106a pp. 17

[4]. American Society of Agricultural Biological Engineer (ASABE) (2005). The Last Mile Problem In The Information Highway: Improving The Reach of Farmers In Developing Countries: Proceedings of The World Congress of Computers In Agricultural and Natural Resources (13-15, March 2002, Iguacu Falls, Brazil) 701p0301. P.779-785 hq@asabe.org.

[5]. Androulidakis, S.I., Siados, G.C., and Crunkilton, J.R. (1995). Perceptions of Agricultural Extension Agents of Their Effecti veness to Reach Farmers in a Selected Area of Macedonia, Agricultural Extension Education, 2 (1), 2-9.

[6]. Olowu, T.A. and Windapo, O. (1995). Managing Research Extension End-Users Interface: Lessons from Nigeria. In Afolayan, S.O and Akinbode, J.A (eds). Issues and priorities for Nigerians Agricultural Extension in the $21^{\text {st }}$ Century.Proceedings of the Inaugural Conference of the Agricultural Extension Society of Nigeria, AMTI, Ilorin. 